\title{
The Cuticle Mutant eca2 Modifies Plant Defense Responses to Biotrophic and Necrotrophic Pathogens and Herbivory Insects
}

\author{
Catherine Blanc, ${ }^{1}$ Fania Coluccia, ${ }^{1}$ Floriane L'Haridon, ${ }^{1}$ Martha Torres, ${ }^{2}$ Marlene Ortiz-Berrocal, ${ }^{2,3}$ \\ Elia Stahl, ${ }^{3}$ Philippe Reymond, ${ }^{3}$ Lukas Schreiber, ${ }^{4}$ Christiane Nawrath, ${ }^{3}$ Jean-Pierre Métraux, ${ }^{1}$ and \\ Mario Serrano ${ }^{2, \dagger}$ \\ ${ }^{1}$ Department of Biology, University of Fribourg. Chemin du Musée 10, 1700 Fribourg, Switzerland; ${ }^{2}$ Centro de Ciencias \\ Genómicas, Universidad Nacional Autónoma de México, Av. Universidad 2001, 62209, Cuernavaca, Morelos, México; \\ ${ }^{3}$ Department of Plant Molecular Biology, University of Lausanne, 1015 Lausanne, Switzerland; ${ }^{4}$ Institute of Cellular and \\ Molecular Botany, Department of Ecophysiology, University of Bonn, Kirschallee 1, D-53115 Bonn, Germany
}

Accepted 10 November 2017.

\begin{abstract}
We isolated previously several Arabidopsis thaliana mutants with constitutive expression of the early microbe-associated molecular pattern-induced gene $A T L 2$, named eca (expresión constitutiva de $A T L 2)$. Here, we further explored the interaction of eca mutants with pest and pathogens. Of all eca mutants, eca2 was more resistant to a fungal pathogen (Botrytis cinerea) and a bacterial pathogen (Pseudomonas syringae) as well as to a generalist herbivorous insect (Spodoptera littoralis). Permeability of the cuticle is increased in eca2; chemical characterization shows that $e c a 2$ has a significant reduction of both cuticular wax and cutin. Additionally, we determined that eca2 did not display a similar compensatory transcriptional response, compared with a previously characterized cuticular mutant, and that resistance to $B$. cinerea is mediated by the priming of the early and late induced defense responses, including salicylic acidand jasmonic acid-induced genes. These results suggest that ECA2-dependent responses are involved in the nonhost defense mechanism against biotrophic and necrotrophic pathogens and against a generalist insect by modulation and priming of innate immunity and late defense responses. Making eca 2 an interesting model to characterize the molecular basis for plant defenses against different biotic interactions and to study the initial events that take place in the cuticle surface of the aerial organs.
\end{abstract}

During their lifespan, plants are affected by multiple environmental stresses caused by excessive variations in water, light, wind, or attacks by herbivores and pathogens. Plants have evolved diverse constitutive barriers to survive such challenges. For instance, they are equipped to perceive and build-up defensive responses against microorganisms. Chemical molecules called microbe-, pathogen-, herbivore-, or damage-associated

Funding: This work was supported by the Dirección General de Asuntos del Personal Académico-Universidad Nacional Autónoma de México (UNAM) grant PAPIIT RA200316 and the Swiss National Science Foundation grants 31003A_146276, 31003A_149286, and 31003A_170127.

${ }^{\dagger}$ Corresponding author: Mario Serrano; E-mail: serrano@ccg.unam.mx

*The $\boldsymbol{e}$-Xtra logo stands for "electronic extra" and indicates that four supplementary figures and two supplementary tables are published online.

(c) 2018 The American Phytopathological Society molecular patterns (MAMPs, PAMPs, HAMPs, or DAMPs) released during the interaction with microbes are recognized by pattern recognition receptors (PRRs) (Boller and Felix 2009). This triggers a first line of defense named PAMP-triggered immunity (PTI) (Conrath et al. 2015; Zipfel 2014) that includes a broad spectrum of defenses such as structural changes, antibiotic proteins, or metabolites. Pathogens often produce effectors that interfere with the activation of PTI. Effectors can be recognized by specific resistance proteins, leading to a so-called effector-triggered immunity (ETI) or gene-for-gene resistance (Craig et al. 2009; Jones and Dangl 2006). The combined effect of such mechanisms, called nonhost resistance, can block efficiently the invasion of genetic variants of nonadapted pathogens, both locally at the infection site and systemically in uninfected leaves (Craig et al. 2009; Tsuda and Somssich 2015). Remarkably, since nonhost resistance is typically both broad-spectrum and durable, it has considerable value for crop improvement (Lee et al. 2016). Interestingly, PTI and ETI share similar molecular defenseresponse elements but with different dynamics in the activation and intensity (Katagiri and Tsuda 2010).

On the aerial organs, the first events during a plant-microbe interaction mostly take place at the level of the cuticle. Cutin and wax monomers are the major components of the cuticle and provide a physical barrier to avoid water loss and protection against irradiation, xenobiotics, and pathogens (Nawrath et al. 2013). Once pathogens degrade and penetrate the cuticle, different chemical components are released, including DAMPs and MAMPs, which are potentially perceived by the invading fungi and by the plant, activating multiple processes during pathogenesis. Several reports have shown that Arabidopsis thaliana and Solanum lycopersicum mutants affected in the synthesis of cutin monomers display increased cuticle permeability, induction of the plant innate immunity, and resistance to Botrytis cinerea (Serrano et al. 2014). One hypothesis to explain these responses is that once $B$. cinerea spores have landed on the more permeable leaf surface, molecules such as MAMPs and DAMPs can be, one or both, more rapidly or efficiently recognized leading to the establishment of plant innate immunity. However, the molecular details of the perception of leaf DAMPs and induced responses are not yet well-characterized.

Perception of invaders activates a cascade of responses that differ in their timing but culminate in the production of a barrier that eventually blocks the invader (Boller and Felix 2009). One to five minutes after activation of PRRs, the generation of 
reactive oxygen species (ROS), calcium $\left(\mathrm{Ca}^{2+}\right)$ influx, protein phosphorylation, and mitogen-activated protein kinase (MAPK) signaling take place (de la Fuente van Bentem and Hirt 2007; Lehmann et al. 2015; Nühse et al. 2000; Wendehenne et al. 2002). Between 5 to 30 min after activation of PRRs, ethylene (ET) accumulation, endocytosis of PRRs, and transcriptional reprograming of early response genes (ERGs) are observed that lead to the amplification of the immune responses (Robatzek et al. 2006; Spanu et al. 1994; Tsuda and Somssich 2015; Tullai et al. 2007). Additionally, programmed cell death or hypersensitive response has been described as part of the immune response and is regulated by the ROS accumulated during the plantpathogen interactions (Bellin et al. 2013; Lehmann et al. 2015). Finally, after hours or days, late defense responses are induced, including accumulation of toxic secondary metabolites, production of histological barriers such as callose or lignin, and the induction of phytohormone-induced signaling pathways that bring other parts of the plant to a state of alert and defense (Dangl et al. 2013; Garcion et al. 2007).

Perception of two bacterial-derived PAMPs, flg22 or elf18 by plant receptors FLS2 and EFR, respectively, induce similar sets of ERGs (Zipfel et al. 2004, 2006). Remarkably, DAMPs and MAMPs released during the interaction with one or both the necrotrophic fungus $B$. cinerea or treatment with chitin also induce the similar transcriptional signature of ERGs (Ferrari et al. 2007; Ramonell et al. 2002). Additionally, HAMPs released during herbivore-plant interaction also induced a similar set of early defense responses, including the transcriptional activation of ERGs (Fürstenberg-Hägg et al. 2013). This suggests that activation of the plant innate immunity by MAMPs or HAMPs, or both, converge at the induction of ERGs. For this reason, ERGs can be used as a starting point to characterize the very early and late immune responses. However, the genetic elements that participate in ERG activation and regulation are not fully characterized.

MAMPS or DAMPs such as chitin, flg22, or cellulose rapidly induce several ERGs named ATLs (A. thaliana lethal) (Guzmán 2012; Hondo et al. 2007; Salinas-Mondragón et al. 1999; Serrano et al. 2006). ATL belongs to a multimembered gene family in A. thaliana and Oryza sativa encoding RING-H2 finger proteins (Guzmán 2012; Hondo et al. 2007; Salinas-Mondragón et al. 1999; Serrano et al. 2006). A genetic approach was used to explore the regulation of ATL2, and five mutants, called eca (expresión constitutiva de ATL2), were identified that displayed constitutive expression of ATL2 (Serrano and Guzmán 2004). Interestingly, all eca mutants show activation of MAMP-induced ERGs and the late-induced defense-related genes NPRI, PAL, and CHS. While some mutants activated other genes, including members of the ATL family and the salicylic acid (SA)- and jasmonic acid (JA)induced genes PRI and PDF2.1 (Serrano and Guzmán 2004). This initial characterization suggests that ECAs might play a role in the regulation of early and late events of the plant innate immunity and on SA- or JA-induced defense responses.

We further studied ECA-mediated defense responses and show that one eca mutant, eca2, is resistant to Pseudomonas syringae, B. cinerea, and Spodoptera littoralis. Priming of innate immune response- and defense-associated genes were observed in eca2. Remarkably, we determined that eca2 is a permeable cuticle mutant with a reduced wax and cutin content and a not previously described transcriptomic profile.

\section{RESULTS}

eca2 is more resistant to the biotrophic bacterium $P$. syringae and to the necrotrophic fungus $B$. cinerea.

The response of eca mutants to pathogens with different lifestyles (biotrophic, hemibiotrophic, or necrotrophic) was determined and results of infection tests against $P$. syringae, Phytophthora brassicae, and B. cinerea are shown in Figure 1. The eca mutants were compared with transgenic Arabidopsis plant ecotype C24 carrying the transcriptional fusion of the ATL2 promoter with the reporter $\beta$-glucuronidase (GUS) gene (Salinas-Mondragón et al. 1999), henceforth identified as wild-type (wt) plants. Infection of eca mutants with $P$. syringae pv. maculicola ES4326 (Zeier et al. 2004) revealed that only eca 2 was more resistant to this pathogen compared with wt plants (Fig. 1A).

Wild-type Arabidopsis ecotype Columbia-0 (Col-0) plants are resistant to Phytophthora brassicae; however, double mutant cyp79B2/cyp79B3 defective in two cytochrome $\mathrm{P} 450$

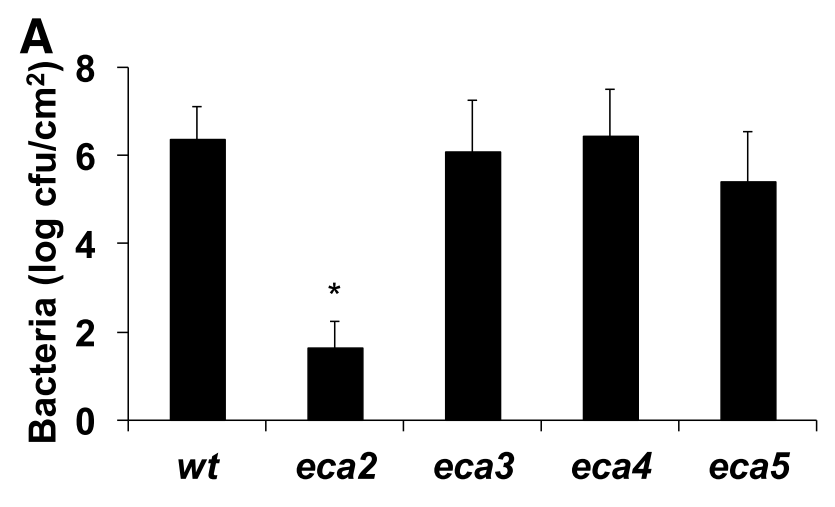

B
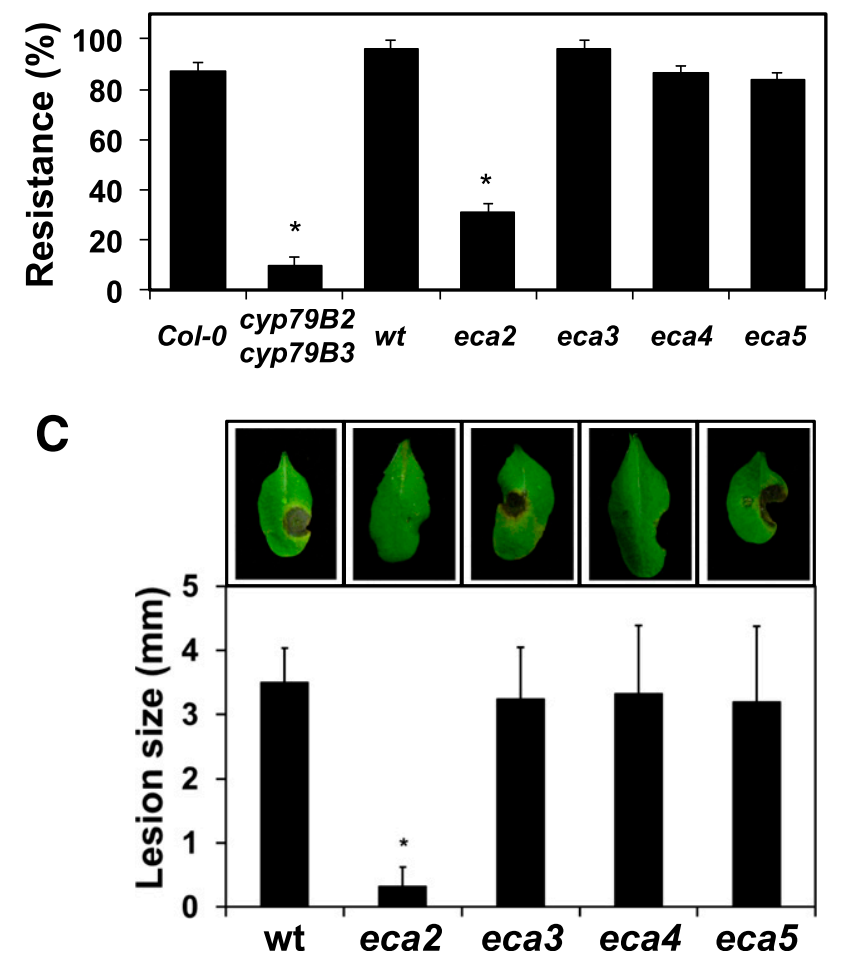

Fig. 1. Infection assay with biotrophic, hemibiotrophic, and necrotrophic pathogens. A, Three leaf disks from three independent 4-week-old Arabidopsis plants inoculated with Pseudomonas syringae pv. maculicola were homogenized to determine colony-forming units per square centimeter 3 days postinoculation (dpi). B, Droplets containing zoospores of Phytophthora brassicae isolate D were placed on 20 leaves from five 4-week-old plants and disease resistance was scored at $5 \mathrm{dpi}$, based on symptom development. C, Twenty leaves from five 4-week-old Arabidopsis plants were infected with Botrytis cinerea and lesion size was measured 3 dpi; representative pictures of necrosis caused by $B$. cinerea are included above each histogram as a visual illustration. Bars represent mean values $( \pm$ standard deviation) of three independent experiments. Asterisks indicate a statistically significant difference between wild type and mutants, according to the Student's $t$ test $(P \leq 0.05)$. 
enzymes that catalyze the conversion of tryptophan to indol-3aldoxime have been shown to be susceptible to this pathogen (Schlaeppi et al. 2010; Zhao et al. 2002). To determine if eca mutants present changes during the interaction with this pathogen, we compared them to the double mutant cyp79B2/ cyp79B3 and their corresponding wt plants (Fig. 1B). At 5 days postinoculation (dpi), only eca2 showed enhanced susceptibility to Phytophthora brassicae. However, this phenotype was not as strong as in the double mutant but significantly different from wt plants. At the cytological level, we observed that cell death and hyphal penetration could be detected at $12 \mathrm{~h}$ postinoculation (hpi) in eca2, while this occurred already at 6 hpi in the cyp79B2/cyp79B3 double mutant (Supplementary Fig. 1A).

Only the eca2 mutant showed significant resistance to B. cinerea at 72 hpi (Fig. 1C). To further characterize this observation, the fungal growth was followed by trypan blue staining. At $24 \mathrm{hpi}$, no differences on hyphal development between wt and eca 2 leaves were observed. However, at 48 hpi, hyphal growth of $B$. cinerea on eca2 leaves was strongly inhibited. This indicates that, while the initial compatible interaction between $B$. cinerea and $A$. thaliana might not be affected in eca 2 mutants, the progression of the infection is inhibited.

\section{Early and late plant defense responses are primed in eca2.}

A link between early induced ROS accumulation and resistance to $B$. cinerea has been previously described (L'Haridon et al. 2011). To investigate if eca2-mediated resistance to $B$. cinerea is linked with changes in the basal level of ROS, we performed a histological analysis on noninfected leaves (Fig. 2A). We used 5(and-6)-carboxy-2,7-dichlorodihydrofluorescein diacetate (DCFDA) to detect a broad spectrum of ROS, 3-3' diaminobenzidine (DAB) for $\mathrm{H}_{2} \mathrm{O}_{2}$, and nitroblue tetrazolium (NBT) to detect the production of $\mathrm{O}_{2}^{-}$(Lehmann et al. 2015). Basal accumulation of ROS was increased on eca 2 leaves for all the probes analyzed (Fig. 2A), indicating that ROS are already present before the plant-pathogen interaction takes place.

To further characterize ROS accumulation in eca2 during the interaction with $B$. cinerea, a timecourse experiment was performed (Fig. 2B). Histological analysis using the DCF-DA probe and its densitometric quantification showed that ROS production on wt plants started at $6 \mathrm{hpi}$ and further increased at 12 hpi (Fig. 2B). However, ROS accumulation in eca2 was already detected at $0 \mathrm{hpi}$ and further increased at $3 \mathrm{hpi}$, reaching the highest level at $6 \mathrm{hpi}$, which was maintained until $12 \mathrm{hpi}$ (Fig. 2B). These results suggest that, in comparison with wt plants, the basal level of ROS in eca2 prior to infection are in a primed state that can be rapidly and strongly increased after the interaction with $B$. cinerea.

Defense priming is defined as the sensitization of an organism that leads to a faster and more robust activation of defense responses upon challenge (Conrath et al. 2015). To confirm the possible primed state on eca2, the expression of early and late induced genes related to plant defense were analyzed by quantitative real-time polymerase chain reaction (qRT-PCR), including AIG1 (AVRRPT2-INDUCED GENE 1), the cytochrome P450 CYP79B2, and the pathogen-related protein PRI (Fig. 2C). Expression of all the genes showed a significant increase in eca 2 at 2 hpi compared with the wt plants. However, at $24 \mathrm{hpi}, A I G 1$ and $C Y P 79 B 2$ expression levels were higher on wt than on eca2, while $P R 1$ expression was similar in wt and eca 2 plants (Fig. 2C).

\section{Preliminary genome-wide transcriptomic analysis of eca 2 reveals induction of DNA-binding processes and defense-response genes and repression of $\mathrm{JA}$ responses.}

Early and late defense-response genes are modified in eca mutants (Serrano and Guzmán 2004). To gain a more complete overview, the transcriptome was analyzed in eca 2 using the
DNA microarray of nonchallenged plants (Supplementary Table S1; Supplementary Fig. S2). The basal expression levels of 45 and 56 genes were down- or up-regulated, respectively, in eca 2 compared with wt plants. Some of the repressed genes belonged to a group responsive to chemical stimuli including $\mathrm{JA}$, as indicated by gene ontology (GO) analysis (Supplementary Table 2A). Remarkably, within the 56 genes induced in eca2, we identified several genes including, AIG1 (AVRRPT2INDUCED GENE 1) (Reuber and Ausubel 1996) and MAPK11, that are part of the early induced-defense signaling pathways (Eschen-Lippold et al. 2012). This expression pattern is in agreement with the previous observations related to primed defense responses seen on eca2 (Fig. 2). Furthermore, some of the induced genes in eca2 are related to DNA-binding processes, which is in agreement with the strategy used to identify the eca mutants, since they were selected for their action on the ATL2 promoter (Serrano and Guzmán 2004).

Since the transcriptome was analyzed using only one DNA hybridization, we cannot use these results to perform a rigorous statistical analysis by itself. Nevertheless, to validate these microarray results, the expression of a subgroup of differentially expressed genes (DEGs) related to plant-microbe interactions was analyzed in more detail by qRT-PCR. The anthocyanin biosynthesis-related dihydroflavonol 4-reductase $(D F R)$ gene was indeed found to be under negative regulation in eca2, as detected on the microarray. Conversely, the glucosyltransferase gene (UGT76B1) (von Saint Paul et al. 2011) and the plant natriuretic peptide A $(P N P-A)$ involved in SA-mediated defense signaling were induced in eca2 (Meier et al. 2008).

eca 2 is more resistant to nonadapted herbivore $S$. littoralis.

Plant defense responses induced by herbivore attack are driven largely by the synthesis of secondary metabolites, including glucosinolates (GS) that are regulated by the JA pathway (Agrawal et al. 2014; Schweizer et al. 2013). Since we observed a repression of genes modulated by JA, we analyzed the possible effect on the interaction between eca2 and generalist and specialist herbivores, S. littoralis and Pieris brassicae, respectively (Fig. 3). Unexpectedly, a significant reduction by approximately $50 \%$ of larval weight of S. littoralis was observed in eca2-fed samples but not those of Pieris brassicae (Fig. 3). However, the cytochrome P450 CYP79B2 has been described to regulate the biosynthesis of indolic glucosinolates (IGs), which contribute to defense against generalist herbivores (Frerigmann and Gigolashvili 2014). We observed a primed induction of $C Y P 79 B 2$ upon $B$. cinerea infection in eca2 (Fig. 2C). It is possible that similar induction can be triggered after $S$. littoralis infection, and this might explain the reduced larval weight of S. littoralis (Fig. 3A). In addition, the specialist Pieris brassicae is able to detoxify GS and performs equally well on wt or GS mutant plants (Schlaeppi et al. 2008; Schweizer et al. 2013). This last observation supports the role of IGs (and possibly aliphatic GS) in enhanced resistance of eca2 to $S$. littoralis.

\section{eca 2 is a cuticle mutant}

\section{with reduced wax and cutin amount.}

ROS accumulation, induction of plant innate immunity, resistance to $B$. cinerea, and increased cuticular permeability have been observed in A. thaliana and Solanum lycopersicum mutants of cutin monomers biosynthesis (Serrano et al. 2014). Thus, we questioned whether eca 2 was a cuticular mutant. Therefore, the permeability of eca mutants was determined by analyzing chlorophyll leaching and the retention of toluidine blue (Fig. 4A). The eca 2 mutant showed more retention of toluidine blue and significantly more chlorophyll leaching compared with wt plants, suggesting an increased cuticle permeability (Fig. 4A). To relate this observation to other mutants in cuticle formation, the 


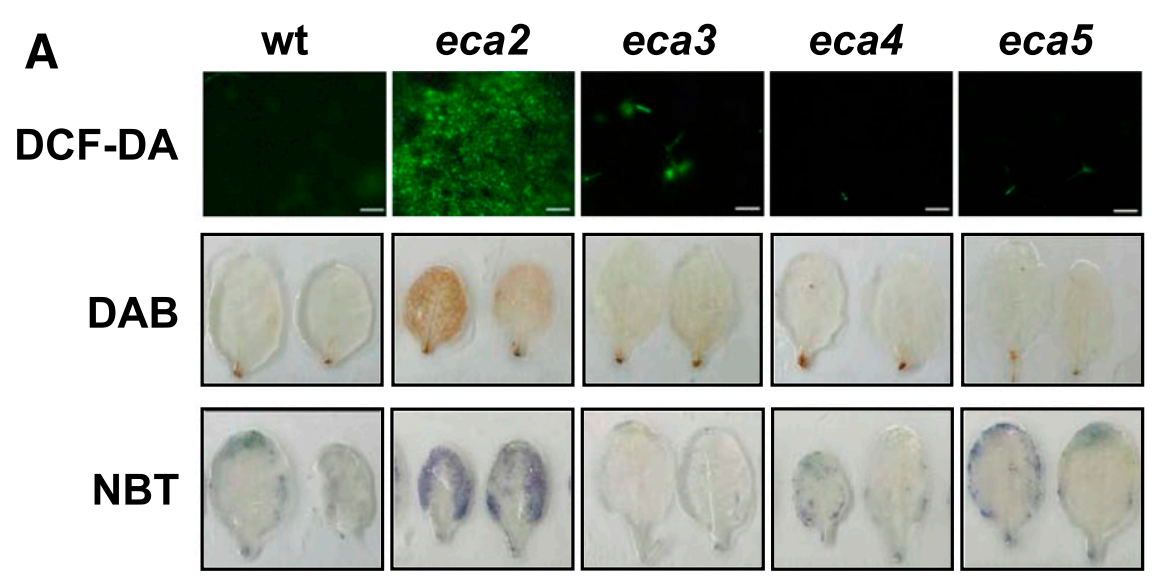

B
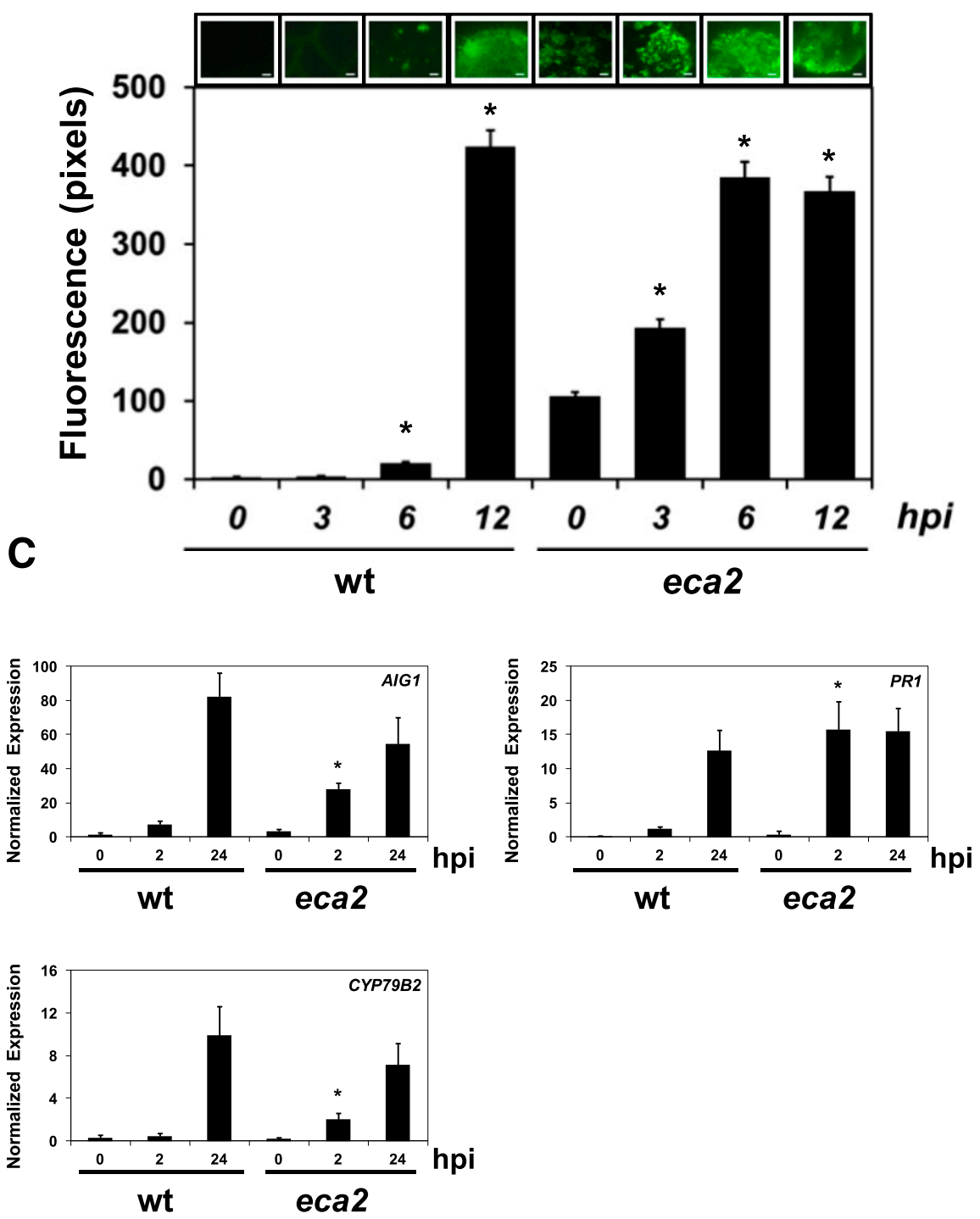

Fig. 2. Analysis of primed defense responses on eca2. A, Leaves from 4-week-old unchallenged Arabidopsis plants were stained using 5-(and-6)-carboxy-2,7dichlorodihydrofluorescein diacetate (DCF-DA), 3-3' diaminobenzidine (DAB), and nitroblue tetrazolium (NBT) to detect basal reactive oxygen species (ROS) levels. Representative pictures of three independent experiments are shown. B, Densitometric quantification of ROS production at indicated timepoints after infection with Botrytis cinerea. Representative pictures of ROS detected after DCF-DA staining are included above each histogram as a visual illustration. Bars represent mean values ( \pm standard deviation) of three independent experiments. Asterisks indicate a statistically significant difference compared with $0 \mathrm{~h}$ postinoculation (hpi), according to the Student's $t$ test $(P \leq 0.05)$. C, Quantitative real-time polymerase chain reaction (qRT-PCR) analysis of defense response genes. The expression of selected genes was determined at 0,2 , and 24 hpi with $B$. cinerea and was normalized with respect to the reference gene AT4G26410, previously described as a stable reference gene (Czechowski et al. 2005). Histograms represent mean values $( \pm$ standard error) of three independent experiments with three technical replicates for each qRT-PCR assay. Asterisks indicate statistical significant differences between wild type and eca 2 at the indicated timepoints, according to Student's $t$ test $(P<0.01)$. Scale bar $=200 \mu \mathrm{m}$. 
permeability of eca2 was compared with bodyguard (bdg) (a member of the $\alpha / \beta$-hydrolase fold protein superfamily) and lacs2-3 (long-chain acyl-CoA synthetase 2) (Bessire et al. 2007; Kurdyukov et al. 2006). lacs $2-3$ and bdg showed an increase in cuticle permeability when compared with their corresponding Col-0 wt plants. Interestingly, no significant differences between eca2, bdg, and lacs 2.3 were observed, indicating a strong impairment in cuticle formation (Fig. 4B).

Cutin and wax are the main constituents of the cuticle and both contribute to the formation of the diffusion barrier (Schreiber 2010). Cutin and wax components of Arabidopsis have been described previously (Li-Beisson et al. 2013; Nawrath et al. 2013). The cuticular components of fully expanded rosette leaves were analyzed in the eca 2 and wt plants (Fig. 5). Typical oxygenated monomers of Arabidopsis leaf cutin were quantified (Nawrath et al. 2013). Most oxygenated C18 monomers were reduced by 20 to $40 \%$, while C16 monomers were unaltered or increased in their amounts, leading to a total reduction in
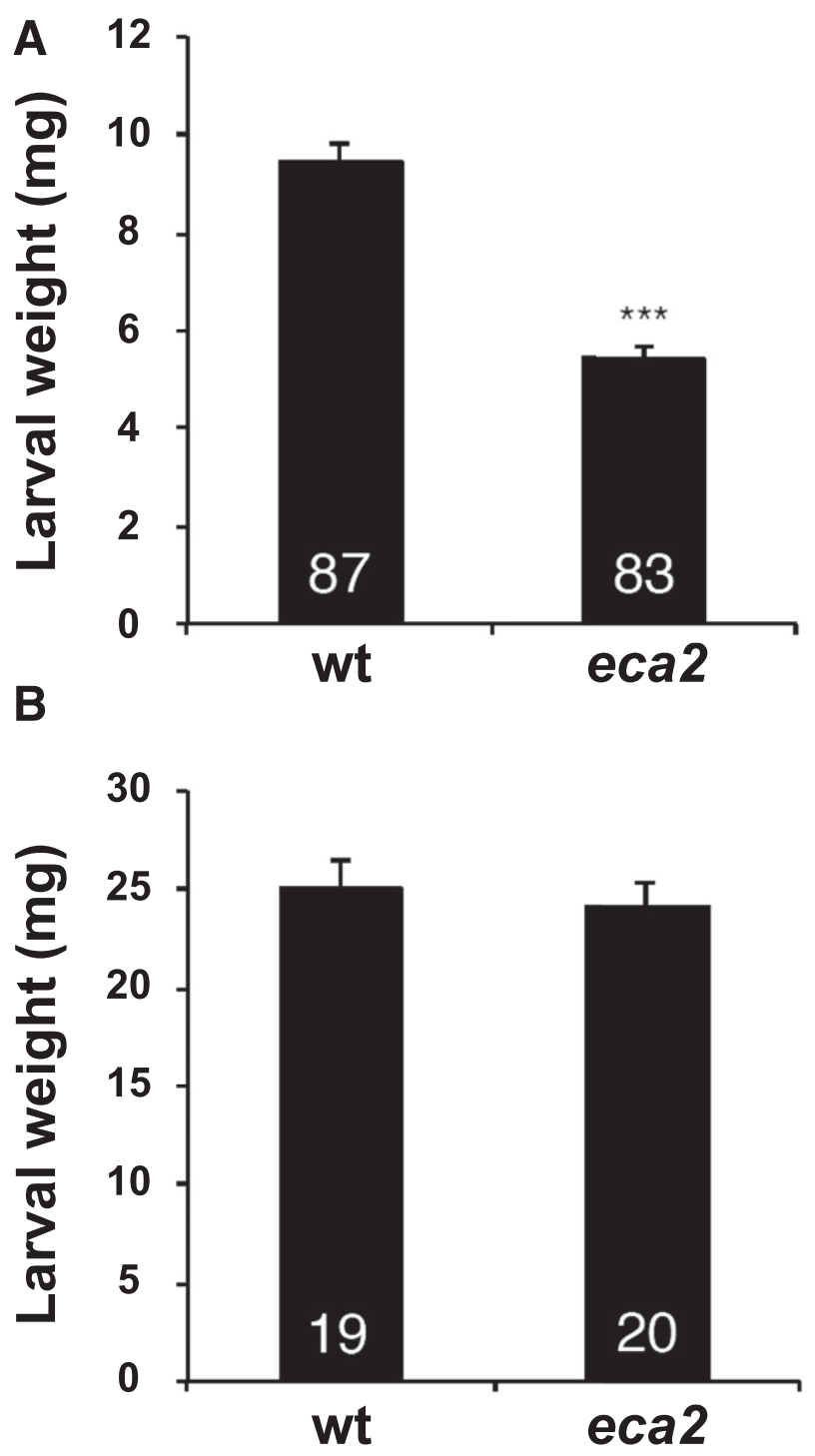

Fig. 3. Performance of a generalist and a specialist herbivore on eca2. Larval performance was tested in no-choice experiments on wild-type plants (wt) and eca2 mutant plants. A, Freshly hatched larvae of the generalist Spodoptera littoralis or B, of the specialist Phytophthora brassicae were placed on 5-week-old plants and larval weight (mean \pm standard error) was measured after 10 days of feeding. The number of larvae measured for each genotype is shown in each bar. Asterisks indicate a statistically significant difference of weight between wt- and eca2-fed larvae, according to the Student's $t$ test $(P \leq 0.001)$. oxygenated cutin monomers by $35 \%$. In contrast, the chemical analysis of the aliphatic wax components deposited on expanded leaves revealed a decrease of components of all main wax classes, i.e., alkanes, acids, alcohols, aldehydes, and esters as well as of different chain lengths (Fig. 5C; Supplementary Fig. S3), summing up to a total decrease of the wax load by $55 \%$ (Fig. 5D). The eca2 mutant has, thus, a reduction in the amounts of both wax and cutin being the likely cause of the increased permeability of the cuticle of eca2 plants (Sadler et al. 2016).

eca2 did not present similar compensatory transcriptional response to the reduction of wax and cutin as the cuticular mutant $b d g$.

To compare the transcriptional profile between eca2 and other previously characterized cuticular mutants, we identified the commonly expressed genes on noninfected plants (Supplementary Fig. S4). The Arabidopsis thaliana cuticular mutants lacerata (lcr), fiddlehead ( $f d h)$, and bdg previously showed, as part of a compensatory transcriptional response, a set of DEGs related to the synthesis of wax, cutin, cell-wall, and defense responses (Voisin et al. 2009). DEGs induced in eca2 are not part of the same core of genes present in these mutants, and only one gene was found in common with $f d h$. Additionally, no common downregulated genes were detected among the three mutants. Since the transcriptome was analyzed using only one

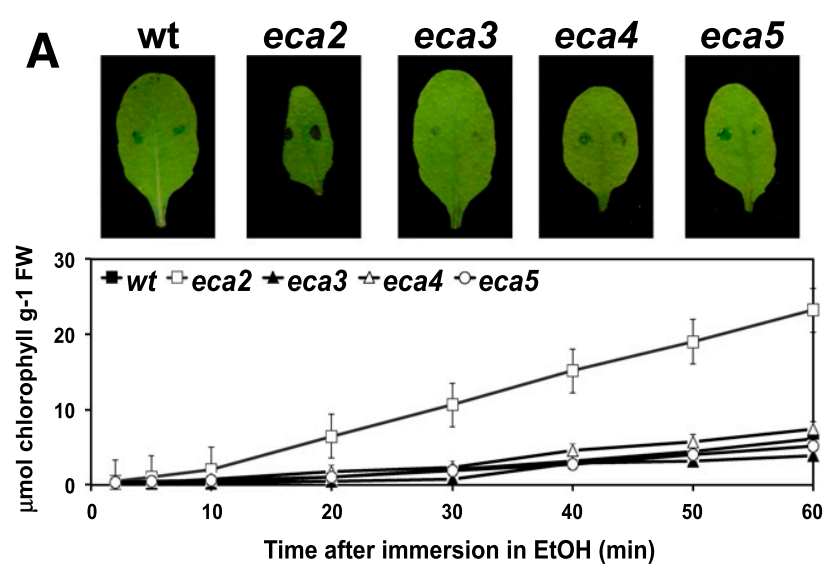

B

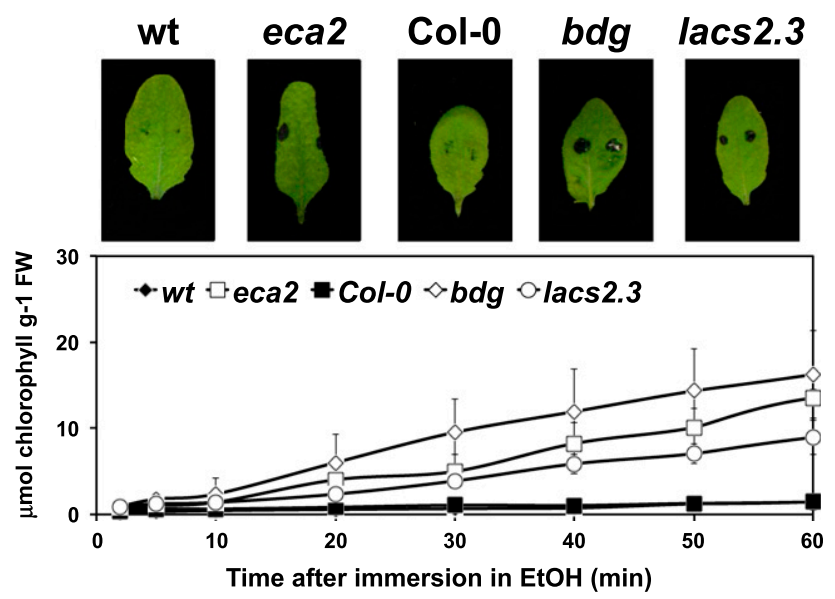

Fig. 4. $\mathbf{A}$ and $\mathbf{B}$, Cuticle permeability is modified in eca2. Upper panels, a droplet of toluidine blue was placed on the leaf surface for $2 \mathrm{~h}$ and was then rinsed with water. The blue stain remains attached to the cell wall if the plant has a more permeable cuticle. Representative pictures of three independent experiments are included. Lower panels, leaves from six 4-weekold plants were placed in ethanol and the release of chlorophyll was followed over the indicated time. The values represent mean of three independent samples \pm standard deviation. 
DNA hybridization, we cannot use these results to perform a rigorous statistical analysis by itself. However, to validate these microarray results, the expression of four genes expressed in the previously characterized cuticular mutant $b d g$ (Voisin et al. 2009) were analyzed (Fig. 6). The expression of a member of the 3ketoacyl-CoA synthase family involved in the biosynthesis of very long chain fatty acids (DAISY), the alcohol-forming fatty acyl-CoA reductase (CER4), glucose-methanol-choline oxidoreductase family protein (HTL7), and the lipid transfer protein 4 (LTP4), involved on the synthesis of cuticle were analyzed by
qRT-PCR (Fig. 6). No significant differences in the expression level of DAISY and LPT4 were detected between wt and Col0 control plants, while CER4 and HTL7 shown a slight induction on Col-0, suggesting a possible background-dependent regulation. Nevertheless, interestingly, all the analyzed genes were statistically significantly up-regulated in $b d g$ but not in eca2, compared with the respective control wt plants (Fig. 6). These results suggest that, compared with the other mutants, eca2 did not present similar compensatory transcriptional responses related to its cuticle defects.
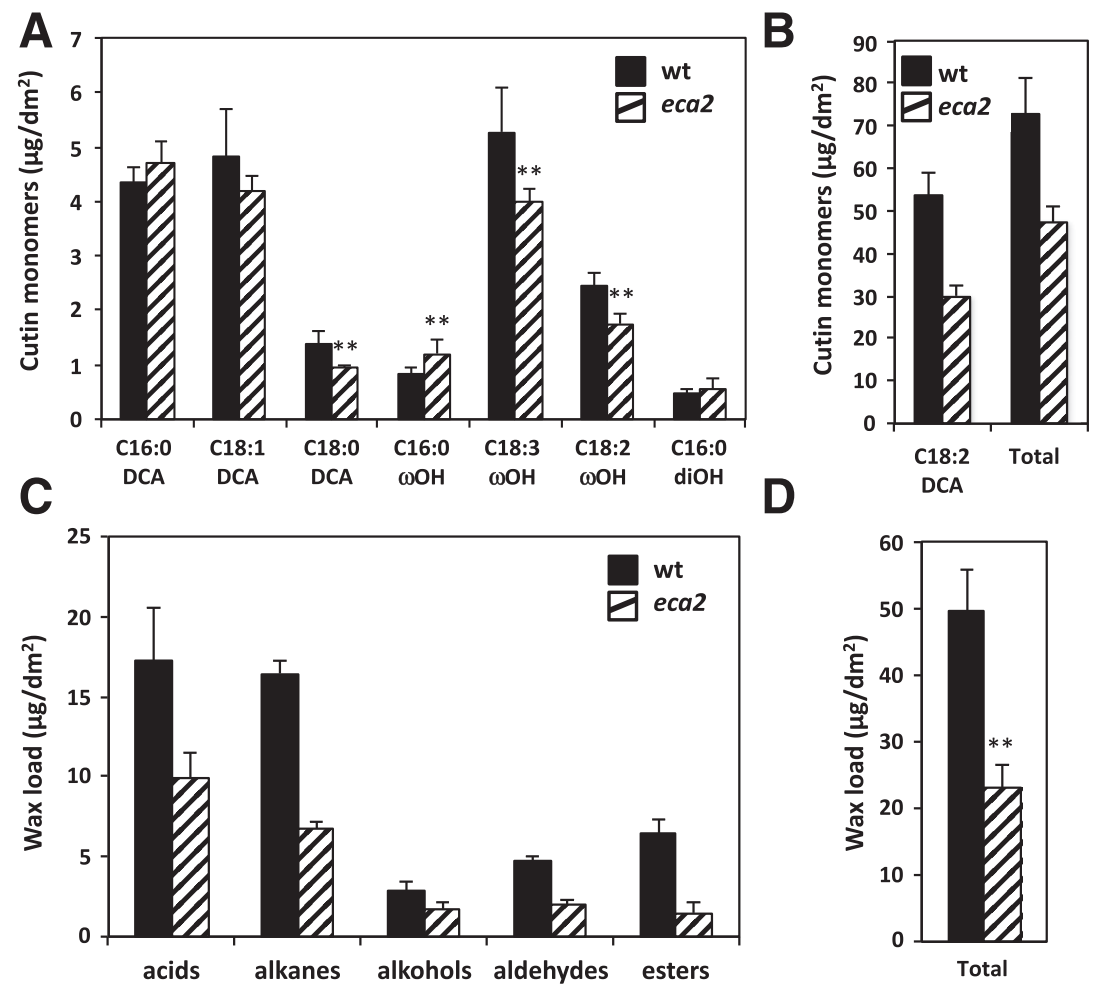

Fig. 5. Analysis of aliphatic cutin monomers and wax components in expanded leaves. A, Composition of minor oxygenated cutin monomers, B, amount of main cutin monomer and the all-oxygenated cutin monomers, $\mathbf{C}$, amount of aliphatic wax components of different classes, and $\mathbf{D}$, total wax content. Values are the mean of five to six replicate samples ( \pm standard deviation). Asterisks indicate a statistically significant difference compared with wild type (wt) samples, according to the Student's $t$ test $(P \leq 0.01)$. The cutin analysis was repeated three times and the wax analysis two times with similar results.
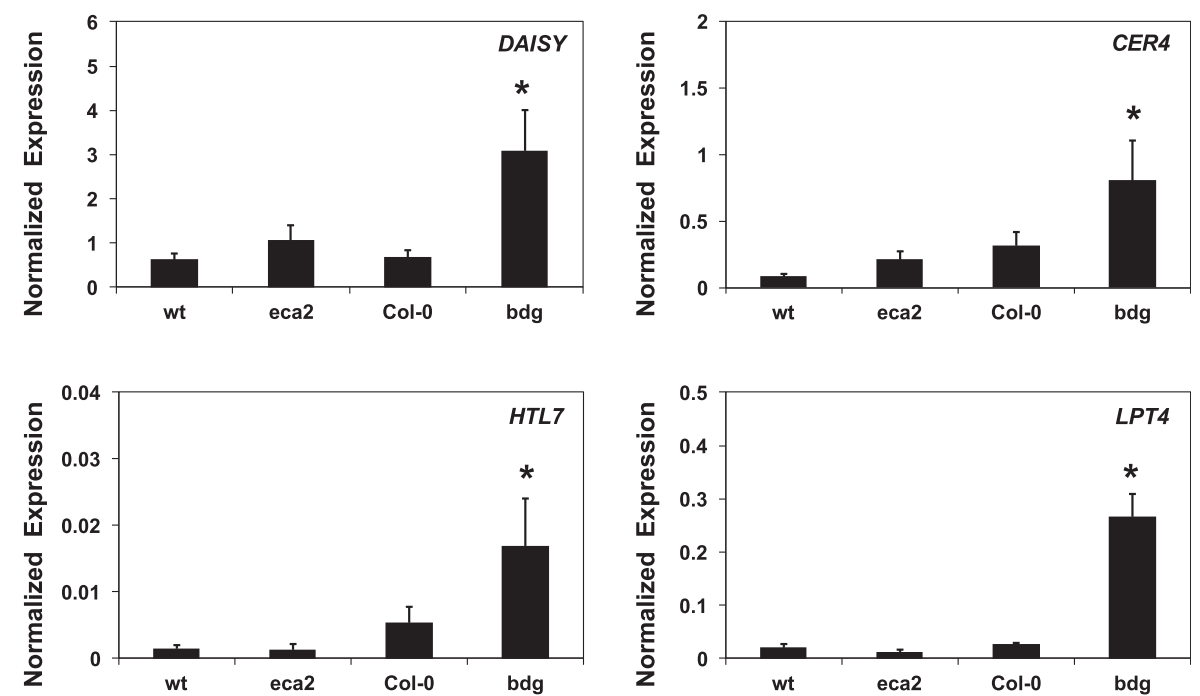

Fig. 6. Analysis of cuticular-related compensatory transcriptional responses. Quantitative real-time polymerase chain reaction (qRT-PCR) analysis of selected differentially expressed genes. The expression of selected genes was determined from noninfected leaves and was normalized with respect to the reference gene AT4G26410, previously described as a stable reference gene (Czechowski et al. 2005). Histograms represent mean values ( \pm standard error) of three independent experiments with three technical replicates for each qRT-PCR assay. Asterisks indicate statistical significant differences to their corresponding wild type and mutants, according to Student's $t$ test $(P<0.01)$. 


\section{DISCUSSION}

The analysis of ERGs characteristic for a physiological response has proven useful for a further description and understanding of its molecular basis. For example, auxin-responsive ERGs have led to the identification and characterization of molecular elements that participate in the perception and action induced by this phytohormone (Dinesh et al. 2016). Here, we further studied ERGs belonging to the plant-specific multigene family ATL that are induced during plant-pathogen interactions after perception of MAMPs such as chitin or flg22 (Guzmán 2012; Hondo et al. 2007; Salinas-Mondragón et al. 1999; Serrano et al. 2006). To investigate the regulation of ATL2, we isolated a set of eca mutants that constitutively expressed ATL2 (Serrano and Guzmán 2004). A preliminary characterization indicated that ECAs play a role not only on the transcriptional regulation of ATL2 but also of other ATL members and MAMP-induced ERGs. However, detailed characterization of eca mutants during plant-microbe interactions was missing. In this work, the response of eca mutants was examined during the interaction with pathogens of different lifestyles, and we showed that eca2 is more resistant to the biotrophic pathogen $P$. syringae, to the necrotrophic $B$. cinerea, as well as to the generalist herbivore $S$. littoralis but is susceptible to Phytophthora brassicae, a hemibiotrophic organism, and does

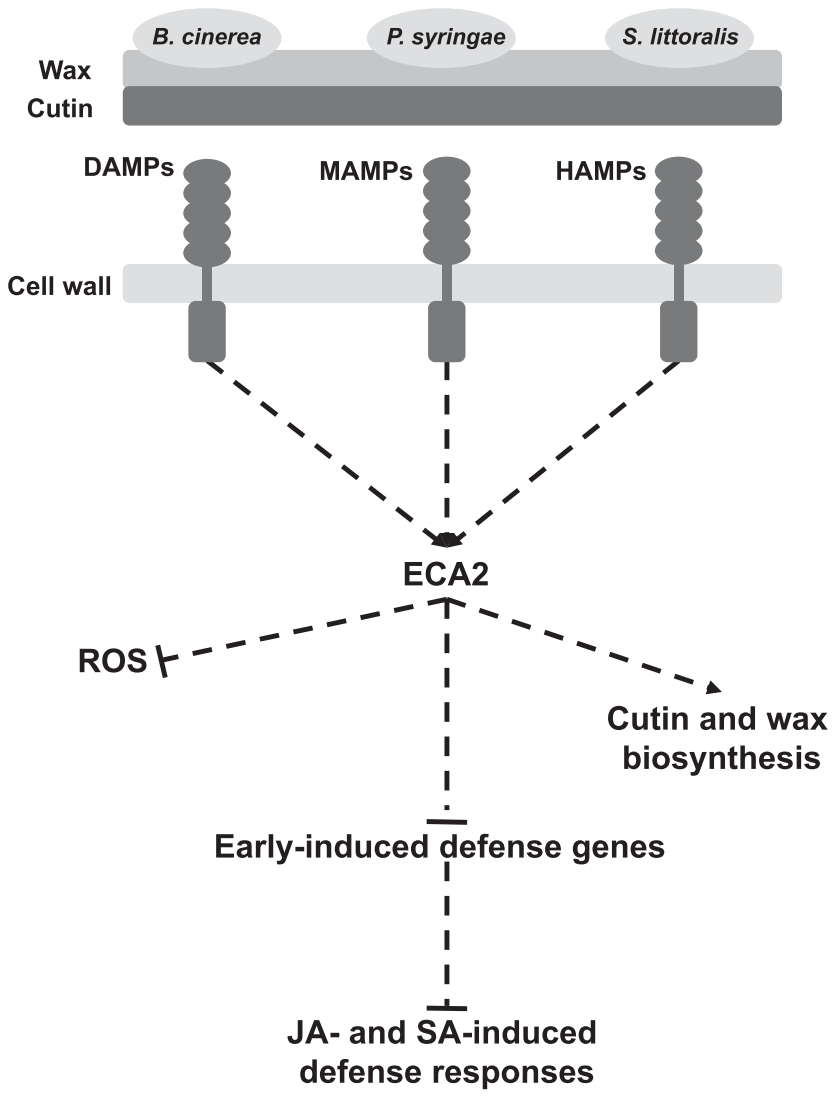

Fig. 7. Hypothetical model of ECA2-dependent defense responses. Plants are always under the effect of different abiotic stimuli, including different lifestyle pathogens. Once these pathogens arrived on the leaf surface, damage-, microbe-, and herbivore-associated molecular patterns (DAMPs, MAMPs and HAMPs) are released and detected by plant receptors inducing the plant innate immunity. We proposed that ECA2 is part of the regulatory machinery that regulates plant innate immunity and, subsequently, the amplification and establishment of the late defense responses. These defense mechanisms are primed on eca2, probably due to a more permeable cuticle, caused by a decrease in cutin and wax content, that leads to an inhibition of the infection of biotrophic and necrotrophic pathogens and herbivory insects. The precise mechanism causing the reduction in cutin and wax load is still unknown. not affect performance of the specialist herbivore Pieris brassicae (Figs. 1 and 3). These results indicate that ECA2-dependent responses appear to be involved in defenses against biotrophic and necrotrophic but not hemibiotrophic pathogens and against a generalist herbivore but not an adapted herbivore. The mutant eca 2 is, therefore, an interesting model to analyze both early and late defense responses induced by Arabidopsis during the interaction with highly diverse pests and pathogens (Fig. 7).

ROS accumulation and early activation of defense response genes are modified in eca 2 during the plant innate immune response (Fig. 2). In eca2, ROS are constitutively accumulated in noninfected plants and increased faster and further (compared with wt) after interaction with $B$. cinerea, suggesting a primed defense response. ROS have been involved in multiple processes during plant-microbe interactions, including the reinforcement of the cell wall, regulation of plant hormone signaling pathways, and triggering of programmed cell death (Lehmann et al. 2015). Interestingly, NADPH oxidase mutants AtRbohD and AtRbohF, which show low production of ROS, are impaired in innate immune responses (Kadota et al. 2015), and an inhibition of SA biosynthesis is observed in these mutants that exhibit susceptibility against $P$. syringae (Chaouch et al. 2012). Interestingly, a direct link between ROS increase and resistance to $B$. cinerea has been previously reported (Benikhlef et al. 2013; Chassot et al. 2007; L'Haridon et al. 2011; Survila et al. 2016). On the other hand, eca2 plants shown a constitutive expression of early PAMP-induced defenseresponse genes $A I G 1$ (AVRRPT2-INDUCED GENE 1) and MAPK11. AIG1 is expressed after $P$. syringae infection (Reuber and Ausubel 1996), while MAPK11 has been described to be induced during the ETI and PAMP-triggered immunity (Bethke et al. 2012; Eschen-Lippold et al. 2012, 2016). Recently, similar phenotypes to eca2 have been reported for the ET-responsive transcription factor AtERF15, which regulates different layers of plant immunity to $P$. syringae and $B$. cinerea, including ROS accumulation and activation of defense-response genes (Zhang et al. 2015). Several reports have shown that activation of plant innate immunity by MAMPs from different organisms converges at the induction of a similar set of ERGs (Ferrari et al. 2007; Ramonell et al. 2002; Zipfel et al. 2004, 2006). Hence, we suggest that ECA2 is part of a negative regulatory machinery that regulates the transcriptional activation of early-induced defenseresponse genes and its mutation causes priming of the plant defense responses that leads to a broad resistance against biotrophic, necrotrophic, and generalist herbivore pathogens (Fig. 7).

After recognition and induction of early responses, amplification of the signal involves SA-, JA-, and ET-dependent signaling pathways (Dangl et al. 2013; Garcion et al. 2007). For instance, resistance against $P$. syringae has been described to rely on SA-dependent signaling (Grant and Jones 2009; Verhage et al. 2010), while the plant defenses against $B$. cinerea and herbivore attack are dependent on one or both JA or ET (Agrawal et al. 2014; Glazebrook 2005; Schweizer et al. 2013; Thomma et al. 2001). To determine if ECA2-dependent defense responses are involved in the regulation of one or both the SAor JA-signaling pathways, we have analyzed the expression of SA- and JA-induced genes. Under nonchallenging conditions, the SA-responsive genes $U G T 76 B 1$ and $P N P-A$ were induced in eca2, while $P R 1$ expression was primed after the interaction with $B$. cinerea (Fig. 2). Interestingly, we observed a repression of genes modulated by JA, but, once eca 2 plants were infected with $B$. cinerea, we detected a primed induction of $C Y P 79 B 2$ that is involved in GS biosynthesis that is regulated by the JA pathway (Agrawal et al. 2014; Schweizer et al. 2013). Taken together, these results suggest a priming of SA- and JA-induced genes in eca2. Primed plants respond to very low levels of a stimulus, including the perception of PAMPs, MAMPs, HAMPs, 
or DAMPs, singly or in combination, in a faster and stronger manner than do unprimed plants in the local and systemic or unchallenged parts of the plant (Conrath 2009). For this reason, primed plants can show more rapid and robust activation of defense responses once interacting with pathogens and pests, which leads to a more efficient establishment of the resistance (Conrath et al. 2015). The often-contradictory results observed in phytohormone-dependent defenses against biotrophic and necrotrophic pathogens likely results from complex cross-talks between the defense-signaling pathways (Koornneef and Pieterse 2008; Pieterse et al. 2009). Thus, ECA2 is involved in the fast activation of SA- and JA-induced defenses responses; however, the precise level of regulation on the primed pathway modified by ECA2 now needs further clarification.

Changes on the major components of the cuticle, cutin and wax, have an important role during abiotic and biotic interactions, in particular regulating plant-pathogen interactions (Aragón et al. 2017; Reina-Pinto and Yephremov 2009). For instance, defense mechanisms against $B$. cinerea are enhanced in mutants with increased leaf permeability and modified cutin biosynthesis (Bessire et al. 2007; Chassot et al. 2007; Ju et al. 2017; Li et al. 2007; Nawrath et al. 2013; Serrano et al. 2014; Tang et al. 2007; Voisin et al. 2009). One hypothesis to explain these responses is that once $B$. cinerea spores have landed on the more permeable leaf surface, molecules such as MAMPs and DAMPs can be more rapidly or efficiently recognized, leading to the establishment of plant innate immunity (Serrano et al. 2014). Additionally, alteration in the wax composition also has consequences on the interaction with other fungal pathogens. For example, the mutant cer3 has a more permeable cuticle and parts of the pathogenesis process are inhibited, including germination and appressorium formation of powdery mildew Golovinnomyces orontii (Inada and Savory 2011). Additionally, transgenic plants overexpressing the gene $C E R 1$, involved in alkane biosynthesis, showed reduced cuticle permeability but increased susceptibility to the fungus Sclerotinia sclerotiorum (Bourdenx et al. 2011). Moreover, the acyl carrier protein ACP4, involved in the biosynthesis of cuticular fatty acids, is required to perceive the mobile systemice acquired resistance (SAR) signal in distal tissues of $A$. thaliana. The acp 4 mutant is able to generate the mobile signal required for SAR induction but was unable to induce a systemic response against the bacterium $P$. syringae, suggesting that loss of signal perception in acp 4 is related to defective cuticles (Xia et al. 2009). Remarkably, to our knowledge, there is no evidence showing that cuticle mutants are resistant to the herbivorous caterpillar S. littoralis, as we observed on eca2. Finally, we determined that eca2 is more susceptible to Phytophthora brassicae (Fig. 1B). It is worth to mentioning that we have determined that the cuticular mutants $b d g$ and lacs 2.3 are also susceptible to Phytophthora brassicae (data not shown), suggesting that impairment of cuticle permeability might be important for resistance against this hemibiotrophic organism; however, further experiments would be needed to clarify this observation.

$e c a 2$ has a strong reduction in both wax and cutin but did not present transcriptional compensatory mechanisms related to this phenotype, which have not been described before (Nawrath et al. 2013; Sadler et al. 2016). A previous transcriptional analysis of the cuticle mutants $l c r, f d h$, and $b d g$ revealed a set of DEGs related to the synthesis of wax, cutin, cell wall, and defense response (Voisin et al. 2009). Comparing these DEGs, we showed that the basal genome-wide transcriptional profile of eca 2 did not share a similar signature, in particular to the cuticular mutant $b d g$ (Fig. 6). Interestingly, these previously characterized mutants presented organ fusion, and this suggests that the transcriptional changes are part of compensatory mechanisms related to this development-related phenotype (Voisin et al. 2009), which is not present on eca2. Nevertheless, in a comparison of the eca2 transcriptional profile with another cuticle mutant with no organ fusion, lacs 2 , which is only compromised in cutin formation (Bessire et al. 2007), once more, no similarities are observed on DEGs (data no shown), suggesting that eca 2 possesses a different transcriptional profile, in particular to the cuticular mutant $b d g$. Interesting, fatty acids have been described not only as a source of reserve energy and essential components of membrane lipids but to play a role during plant defense mechanisms (Kachroo and Kachroo 2009). Additionally, modification of the carbon flux through cytosolic acetyl-CoA by the synthesis of polyhydroxybuturate has been shown to reduce the amount of wax and cutin to similar extents (Xing et al. 2014). Thus, the specific reduction in $\mathrm{C} 18$-derived cutin monomers and $\mathrm{C} 18$ derived metabolites (wax components and JA) might indicate a modification of the early fatty acid metabolism in eca2.

In summary, we found that the cuticle mutant eca 2 is resistant to $B$. cinerea, $P$. syringae, and $S$. littoralis. This suggests that ECA2-dependent responses are involved in the nonhost defense mechanism against biotrophic and necrotrophic pathogens and against a generalist insect. These phenotypes might be due to the efficient and fast activation of the defense responses on eca2, including ROS accumulation and transcriptional induction of the early and late induced defense-response genes (Fig. 7). Additionally, we have shown that eca2 is the first described cuticular mutant with reduced cutin and wax content and with a different transcriptional profile among the previously characterized cuticle-related mutants, in particular to $b d g$. These results make eca 2 an interesting model to characterize the molecular basis of defenses against various pathogens and to study the initial events during the plant-pathogen interactions that take place in the cuticle surface of the aerial organs. It also shows that screening for mutants with different pests and pathogens is a powerful method to identify cuticle mutants. Nevertheless, we are still far from understanding the precise mechanisms causing the reduction in cutin and wax load on eca2, and further studies are warranted to learn how these changes lead to primed defense responses. Finally, it is worthy to note that eca2 was characterized as a single recessive mutation (Serrano and Guzmán 2004). However, we cannot be completely sure that we are dealing with a single mutation until the genetic identity of ECA2 is revealed; future work is directed to this objective.

\section{MATERIALS AND METHODS}

\section{Plant material and growth conditions.}

A. thaliana ecotype C24 carrying a fusion of the ATL2 promoter to the GUS reporter gene ( $p A T L 2:: G U S$ ), as previously described (Salinas-Mondragón et al. 1999), was used as the wt plant. A. thaliana Col-0 seeds were obtained from the Nottingham Arabidopsis Stock Centre (Nottingham, U.K.). The eca2, eca3, eca4, eca5, lacs 2.3 , and bdg mutants were previously described (Bessire et al. 2007; Kurdyukov et al. 2006; Serrano and Guzmán 2004). Seeds were grown on a pasteurized soil mix of humus and perlite $(3: 1)$, were kept at $4^{\circ} \mathrm{C}$ for 2 days, and then, were transferred to the growth chamber. Plants were grown for 4 weeks in a 12-h light and 12-h dark cycle with 60 to $70 \%$ relative humidity, with day temperatures of 20 to $22^{\circ} \mathrm{C}$ and night temperatures of 16 to $18^{\circ} \mathrm{C}$.

\section{Pathogen inoculation and analysis.}

$P$. syringae pv. maculicola infection was performed as previously described (Zeier et al. 2004). Briefly, overnight logphase cultures were pelleted, were washed three times with $10 \mathrm{mM} \mathrm{MgCl}$, and were diluted in $10 \mathrm{mM} \mathrm{MgCl}_{2}$ to $5 \times 10^{6}$ $\mathrm{CFU}$ per milliliter. The bacterial solutions were infiltrated from the abaxial side into one half of a sample leaf, using a 1-ml 
needleless syringe. Bacterial growth was assessed by homogenizing disks originating from infiltrated areas of three different leaves in $1 \mathrm{ml}$ of $10 \mathrm{mM} \mathrm{MgCl}$, plating appropriate dilutions, and quantifying colony numbers 3 dpi.

Infection with Phytophthora brassicae isolate D (CBS179.89) was performed as previously described (Schlaeppi et al. 2010). Four-week-old Arabidopsis leaves were droplet-inoculated with a zoospore suspension $(50,000$ zoospores per milliliter in $10 \mathrm{mM}$ dextrose). Inoculated leaves were scored for disease resistance on a scale of 0 to 4 as follows: $0=$ completely susceptible leaf, $1=$ outgrowing lesion, 2 = confined lesion covering droplet or plug zone, $3=\mathrm{a}$ few spots observed within the droplet or plug zone, $4=$ no disease symptoms. Mean disease resistance scores were transformed into percent values for comparison of replicate inoculations as previously described (Schlaeppi et al. 2010). Pathogen penetration and dead cells were stained with a solution of ethanolic lactophenol and trypan blue (Roetschi et al. 2001) and were observed using a Leica DMR microscope with bright-field settings. Representative images were selected as visual illustrations.

Strains of $B$. cinerea BMM, provided by B. Mauch-Mani (University of Neuchatel, Switzerland), were grown on $39 \mathrm{~g}$ of Difco (Becton Dickinson) potato dextrose agar per liter. Growth and infection were performed as previously described (L'Haridon et al. 2011). Fungal hyphae and dead plant cells were stained by boiling inoculated leaves for $5 \mathrm{~min}$ in a solution of ethanolic lactophenol trypan blue. Stained leaves were cleared in chloral hydrate ( $2.5 \mathrm{~g}$ per milliliter), at room temperature, by gentle shaking until a colored solution was no longer released. Then, leaves were imbibed in $20 \%$ glycerol for $1 \mathrm{~h}$ and were observed using a Leica DMR microscope with bright-field settings. Representative images were selected as a visual illustration.

\section{Insect bioassays.}

Spodoptera littoralis (Egyptian cotton worm) eggs were obtained from Syngenta (Stein AG) and Pieris brassicae (large white butterfly) was reared in a greenhouse on Brassicae oleracea as described previously (Schlaeppi et al. 2008). Evaluation of insect performance was conducted in nonchoice experiments as described previously (Bodenhausen and Reymond 2007). Experiments were performed with 5-week-old plants in transparent Plexiglas boxes. Briefly, freshly hatched S. littoralis or Pieris brassicae were placed on each genotype for 10 days of feeding. Larvae were then collected and were weighed on a precision balance (Mettler-Toledo). Similar results were obtained in two independent experiments.

\section{Statistical analysis.}

Differences were evaluated using Student's $t$ tests, as indicated in the figures legends. Asterisks above each bar represent statistically significant differences ( $P$ value $\leq 0.05$ or $\leq 0.01$ ).

\section{Detection of ROS.}

ROS were detected using the fluorescent probe DCF-DA (Sigma-Aldrich) as previously described (L'Haridon et al. 2011). Accumulation of $\mathrm{O}_{2}^{-}$and $\mathrm{H}_{2} \mathrm{O}_{2}$ was determined using NBT staining and DAB staining, respectively, as previously described (Chen et al. 1993; Thordal-Christensen et al. 1997). Microscope images of leaves stained with DCF-DA were processed for densitometric quantification with Image $\mathbf{J}$ version 1.44 (NIH). NBT- and DAB-destained leaves were observed using a Leica DMR microscope with bright-field settings. Representative images were selected as visual illustrations.

\section{RNA extraction and genome-wide transcriptomic analysis.}

The wt and eca2 plants were infected with $B$. cinerea by spraying a spore suspension of $2 \times 10^{5}$ spores per milliliter in $1 / 4$ potato dextrose broth (PDB). PDB alone was sprayed on plants for mock control samples. Leaves were collected at 0,2 , and $24 \mathrm{~h}$ postinfection for mock- and Botrytis-infected plants. For genome-wide transcriptomic analysis, total RNA from leaves of five plants and from two independent experiments were extracted and mixed. RNA extraction was performed according to the manufacturer's instructions with the RNeasy mini kit from Qiagen. RNA of wt and eca2 noninfected plants were sent, for further quality check, preparation of biotin-labeled RNA probes, hybridization (one per sample) to GeneChip Arabidopsis ATH1 Genome Arrays, and scanning of the slides, to the Integrated Functional Genomics Core Unit of the Interdisciplinary Center for Clinical Research at the Medical Faculty of the University of Muenster, Germany. All of the above steps were performed according to the manufacturer's instructions. The preprocessing of raw data and the Affymetrix quality control tests and gene expression normalization were performed using the software FlexArray 1.4.1 (McGill University and Génome Québec Innovation Centre, Montreal). Identification of up- and downregulated DEGs from published (Voisin et al. 2009) and from the present data was done from normalized data using the software FiRe 2.2 (Garcion et al. 2006). All DEGs were selected based on their expression ratio $\geq 2$ or $\leq 0.5$.

\section{GO analysis.}

DEGs identified by genome-wide transcriptomic analysis were analyzed and classified into GO classes using the analysis toolkit agriGO, previously described by Du et al. (2010).

\section{Confirmation of microarray results by qRT-PCR.}

From three independent experiments, total RNA from leaves of five plants were extracted and mixed according to the manufacturer's instructions with the RNeasy Mini Kit from Qiagen. Total RNA $(1 \mu \mathrm{g})$ of each sample was retro-transcribed into cDNA according to manufacturer's indications (Omniscript RT kit, Qiagen). For each independent experiment, qRTPCR was performed using Sensimix SYBR green kit (Bioline). qRT-PCR was conducted using a Rotor-Gene 6000 PCR machine. RT-PCR conditions were as follows: an initial $95^{\circ} \mathrm{C}$ denaturation step for $15 \mathrm{~min}$, followed by denaturation for $15 \mathrm{~s}$ at $95^{\circ} \mathrm{C}$, annealing for $30 \mathrm{~s}$ at $60^{\circ} \mathrm{C}$, and extension for $30 \mathrm{~s}$ at $72^{\circ} \mathrm{C}$ for 45 cycles, and analyzed on the Corbett Rotor-Gene 6000 application software. Gene expression values were normalized using the gene AT4G26410, previously described as a stable reference gene (Czechowski et al. 2005). Normalized gene expression was determined using the comparative cyclel threshold method previously described (Schmittgen and Livak 2008). The primers were designed using the Primer 3 software, and primers used to analyze the expression of the indicated gene were DFR (AT5G42800) DFR-fw 5'-GACGACTTATG CAACGCTCA and DFR-rev 5'-TCCGTCAGCTTCTTGGAA CT, UGT76B1 (AT3G11340) UGT76B1-fw 5'-TTTAGCTCACC GTGCAACAG and UGT76B1-rev 5'-CCTTCCGAGCTCGTCA TTAG, $P N P$-A (AT2G18660) PNP-A-fw 5'-AGCTGCTCAAGG AAAAGCTG and PNP-A-rev 5'-TCCCGGCAGAAATCAACT AC, CYP79B2 (AT4G39950) CYP79B2-fw 5'-ACGATCATTTA ACCGCTTGG and CYP79B2-rev 5'-CAGTGAGCATCGGCAG ATAA, AIG1 (AT1G33960) AIG1-fw 5'-TGCCGGACTTCCTA AAGAGA and AIG1-rev 5'-TGCTCTTCTGAATGCCCTTT, PRl (AT2G14610) PR1-fw 5'-TTCTTCCCTCGAAAGCTCAA and PR1-rev 5'-AAGGCCCACCAGAGTGTATG. Expression analysis of DAISY, CER4, HTL7, and LPT4 was performed using the primers previously described (Voisin et al. 2009).

\section{Cuticle permeability analysis.}

Toluidine blue staining was carried out by placing $6-\mu \mathrm{l}$ droplets on the leaf surface of $0.025 \%$ toluidine blue solution 
dissolved in $1 / 4$ PDB. After incubation for $2 \mathrm{~h}$, leaves were washed gently with distilled water to remove excess of the solution from leaves. Representative images were selected as a visual illustration. Chlorophyll extraction and quantification was performed as previously described (Benikhlef et al. 2013). Briefly, leaves were weighed and immersed in $30 \mathrm{ml}$ of $80 \%$ ethanol. Chlorophyll suspension was sampled in the dark at room temperature with gentle agitation at 10, 20, 30, 40, 50, and $60 \mathrm{~min}$ after immersion. The chlorophyll content was determined by measuring absorbance at 647 and $664 \mathrm{~nm}$ and was expressed as the micromolar concentration of total chlorophyll per gram of leaf fresh weight.

\section{Biochemical analysis of cutin and wax composition.}

The composition of wax components and cutin was determined from expanded leaves of 6-week-old rosette plants raised in a 10-h light and 14-h dark cycle with 60 to $70 \%$ relative humidity, with a day temperature of $20^{\circ} \mathrm{C}$ and a night temperature of $18^{\circ} \mathrm{C}$. The preparation and analysis of cutin monomers was described previously (Garroum et al. 2016). Total cuticular wax extracts were prepared as described previously (Greer et al. 2007). The quantification of wax components was performed as previously described (Sadler et al. 2016; Voisin et al. 2009).

\section{ACKNOWLEDGMENTS}

We thank L. Grainger and M. Rebeaud for their invaluable technical assistance and V. Zeisler-Diehl for her help with the wax analysis. We thank P. Guzmán (Centro de Investigación y de Estudios Avanzados del Instituto [CINVESTAV], Irapuato, Mexico) for providing the ATL2p::GUS line and eca mutants. Thanks are also extended to A. Tromas and D. Formey and to the anonymous reviewers for their critical comments. This work was supported by funds from the Swiss National Science Foundation grant to J.-P. Metraux, grant number 31003A_149286 to P. Reymond, and grants 31003A_146276 and 31003A_170127 to C. Nawrath, and from Dirección General de Asuntos del Personal Académico-Universidad Nacional Autónoma de México (UNAM) grant PAPIIT RA200316 to M. Serrano. M Ortiz-Berrocal was supported by a Seed Money Grant for Latin America from the Swiss Government to C. Nawrath and M. Serrano.

\section{LITERATURE CITED}

Agrawal, A. A., Hastings, A. P., Patrick, E. T., and Knight, A. C. 2014. Specificity of herbivore-induced hormonal signaling and defensive traits in five closely related milkweeds (Asclepias spp.). J. Chem. Ecol. 40: 717-729.

Aragón, W., Reina-Pinto, J. J., and Serrano, M. 2017. The intimate talk between plants and microorganisms at the leaf surface. J. Exp. Bot. 68:5339-5350.

Bellin, D., Asai, S., Delledonne, M., and Yoshioka, H. 2013. Nitric oxide as a mediator for defense responses. Mol. Plant-Microbe Interact. 26:271-277.

Benikhlef, L., L'Haridon, F., Abou-Mansour, E., Serrano, M., Binda, M., Costa, A., Lehmann, S., and Métraux, J.-P. 2013. Perception of soft mechanical stress in Arabidopsis leaves activates disease resistance. BMC Plant Biol. 13:133.

Bessire, M., Chassot, C., Jacquat, A. C., Humphry, M., Borel, S., Petétot, J. M. C., Métraux, J. P., and Nawrath, C. 2007. A permeable cuticle in Arabidopsis leads to a strong resistance to Botrytis cinerea. EMBO J. 26:2158-2168.

Bethke, G., Pecher, P., Eschen-Lippold, L., Tsuda, K., Katagiri, F., Glazebrook, J., Scheel, D., and Lee, J. 2012. Activation of the Arabidopsis thaliana mitogen-activated protein kinase MPK11 by the flagellin-derived elicitor peptide, flg22. Mol. Plant-Microbe Interact. 25:471-480.

Bodenhausen, N., and Reymond, P. 2007. Signaling pathways controlling induced resistance to insect herbivores in Arabidopsis. Mol. PlantMicrobe Interact. 20:1406-1420.

Boller, T., and Felix, G. 2009. A renaissance of elicitors: Perception of microbe-associated molecular patterns and danger signals by patternrecognition receptors. Annu. Rev. Plant Biol. 60:379-406.

Bourdenx, B., Bernard, A., Domergue, F., Pascal, S., Léger, A., Roby, D., Pervent, M., Vile, D., Haslam, R. P., Napier, J. A., Lessire, R., and Joubès, J. 2011. Overexpression of Arabidopsis ECERIFERUM1 promotes wax very-long-chain alkane biosynthesis and influences plant response to biotic and abiotic stresses. Plant Physiol. 156:29-45.
Chaouch, S., Queval, G., and Noctor, G. 2012. AtRbohF is a crucial modulator of defence-associated metabolism and a key actor in the interplay between intracellular oxidative stress and pathogenesis responses in Arabidopsis. Plant J. 69:613-627.

Chassot, C., Nawrath, C., and Métraux, J. P. 2007. Cuticular defects lead to full immunity to a major plant pathogen. Plant J. 49:972-980.

Chen, Z., Silva, H., and Klessig, D. F. 1993. Active oxygen species in the induction of plant systemic acquired resistance by salicylic acid. Science 262:1883-1886.

Conrath, U. 2009. Priming of induced plant defense responses. Pages 361-395 in: Advances in Botanical Research, Academic Press, London

Conrath, U., Beckers, G. J. M., Langenbach, C. J. G., and Jaskiewicz, M. R. 2015. Priming for enhanced defense. Annu. Rev. Phytopathol. 53: 97-119

Craig, A., Ewan, R., Mesmar, J., Gudipati, V., and Sadanandom, A. 2009. E3 ubiquitin ligases and plant innate immunity. J. Exp. Bot. 60: 1123-1132.

Czechowski, T., Stitt, M., Altmann, T., Udvardi, M. K., and Scheible, W. R. 2005. Genome-wide identification and testing of superior reference genes for transcript normalization in Arabidopsis. Plant Physiol. 139: 5-17.

Dangl, J. L., Horvath, D. M., and Staskawicz, B. J. 2013. Pivoting the plant immune system from dissection to deployment. Science 341:746-751.

de la Fuente van Bentem, S., and Hirt, H. 2007. Using phosphoproteomics to reveal signalling dynamics in plants. Trends Plant Sci. 12:404-411.

Dinesh, D. C., Calderón Villalobos, L. I., and Abel, S. 2016. Structural biology of nuclear auxin action. Trends Plant Sci. 21:302-316.

Du, Z., Zhou, X., Ling, Y., Zhang, Z., and Su, Z. 2010. agriGO: A GO analysis toolkit for the agricultural community. Nucleic Acids Res. 38 (suppl_2):W64-W70.

Eschen-Lippold, L., Bethke, G., Palm-Forster, M. A. T., Pecher, P., Bauer, N., Glazebrook, J., Scheel, D., and Lee, J. 2012. MPK11-a fourth elicitor-responsive mitogen-activated protein kinase in Arabidopsis thaliana. Plant Signal. Behav. 7:1203-1205.

Eschen-Lippold, L., Jiang, X., Elmore, J. M., Mackey, D., Shan, L., Coaker, G., Scheel, D., and Lee, J. 2016. Bacterial AvrRpt2-like cysteine proteases block activation of the Arabidopsis mitogen-activated protein kinases, MPK4 and MPK11. Plant Physiol. 171:2223-2238.

Ferrari, S., Galletti, R., Denoux, C., De Lorenzo, G., Ausubel, F. M., and Dewdney, J. 2007. Resistance to Botrytis cinerea induced in Arabidopsis by elicitors is independent of salicylic acid, ethylene, or jasmonate signaling but requires PHYTOALEXIN DEFICIENT3. Plant Physiol. 144:367-379.

Frerigmann, H., and Gigolashvili, T. 2014. MYB34, MYB51, and MYB122 distinctly regulate indolic glucosinolate biosynthesis in Arabidopsis thaliana. Mol. Plant 7:814-828.

Fürstenberg-Hägg, J., Zagrobelny, M., and Bak, S. 2013. Plant defense against insect herbivores. Int. J. Mol. Sci. 14:10242-10297.

Garcion, C., Baltensperger, R., Fournier, T., Pasquier, J., Schnetzer, M. A., Gabriel, J. P., and Métraux, J. P. 2006. FiRe and microarrays: A fast answer to burning questions. Trends Plant Sci. 11:320-322.

Garcion, C., Lamotte, O., and Métraux, J. P. 2007. Mechanisms of defence to pathogens: biochemistry and physiology. Pages 109-132 in: Induced Resistance for Plant Defence: A Sustainable Approach to Crop Protection. W. D. Newton, A., and Lyon, G. D., eds. Blackwell Press, Oxford. https://doi.org/10.1002/9780470995983.ch6

Garroum, I., Bidzinski, P., Daraspe, J., Mucciolo, A., Humbel, B. M., Morel, J.-B., and Nawrath, C. 2016. Cuticular defects in Oryza sativa ATP-binding cassette transporter G31 mutant plants cause dwarfism, elevated defense responses and pathogen resistance. Plant Cell Physiol. 57:1179-1188.

Glazebrook, J. 2005. Contrasting mechanisms of defense against biotrophic and necrotrophic pathogens. Annu. Rev. Phytopathol. 43:205-227.

Grant, M. R., and Jones, J. D. G. 2009. Hormone (dis)harmony moulds plant health and disease. Science 324:750-752.

Greer, S., Wen, M., Bird, D., Wu, X., Samuels, L., Kunst, L., and Jetter, R. 2007. The cytochrome P450 enzyme CYP96A15 is the midchain alkane hydroxylase responsible for formation of secondary alcohols and ketones in stem cuticular wax of Arabidopsis. Plant Physiol. 145:653-667.

Guzmán, P. 2012. The prolific ATL family of RING-H2 ubiquitin ligases. Plant Signal. Behav. 7:1014-1021.

Hondo, D., Hase, S., Kanayama, Y., Yoshikawa, N., Takenaka, S., and Takahashi, H. 2007. The LeATL6-associated ubiquitin/proteasome system may contribute to fungal elicitor-activated defense response via the jasmonic acid-dependent signaling pathway in tomato. Mol. PlantMicrobe Interact. 20:72-81.

Inada, N., and Savory, E. A. 2011. Inhibition of prepenetration processes of the powdery mildew Golovinomyces orontii on host inflorescence stems 
is reduced in the Arabidopsis cuticular mutant cer3 but not in cer1. J. Gen. Plant Pathol. 77:273-281.

Jones, J. D. G., and Dangl, J. L. 2006. The plant immune system. Nature 444:323-329.

Ju, S., Go, Y. S., Choi, H. J., Park, J. M., and Suh, M. C. 2017. DEWAX transcription factor is involved in resistance to Botrytis cinerea in Arabidopsis thaliana and Camelina sativa. Front. Plant Sci. 8:1210.

Kachroo, A., and Kachroo, P. 2009. Fatty acid-derived signals in plant defense. Annu. Rev. Phytopathol. 47:153-176.

Kadota, Y., Shirasu, K., and Zipfel, C. 2015. Regulation of the NADPH oxidase RBOHD during plant immunity. Plant Cell Physiol. 56: 1472-1480.

Katagiri, F., and Tsuda, K. 2010. Understanding the plant immune system. Mol. Plant-Microbe Interact. 23:1531-1536.

Koornneef, A., and Pieterse, C. M. J. 2008. Cross talk in defense signaling. Plant Physiol. 146:839-844.

Kurdyukov, S., Faust, A., Nawrath, C., Bär, S., Voisin, D., Efremova, N., Franke, R., Schreiber, L., Saedler, H., Métraux, J.-P., and Yephremov, A. 2006. The epidermis-specific extracellular BODYGUARD controls cuticle development and morphogenesis in Arabidopsis. Plant Cell 18: 321-339.

L'Haridon, F., Besson-Bard, A., Binda, M., Serrano, M., Abou-Mansour, E., Balet, F., Schoonbeek, H.-J., Hess, S., Mir, R., Léon, J., Lamotte, O., and Métraux, J.-P. 2011. A permeable cuticle is associated with the release of reactive oxygen species and induction of innate immunity. PLoS Pathog. 7:e1002148.

Lee, S., Whitaker, V. M., and Hutton, S. F. 2016. Mini Review: Potential Applications of non-host resistance for crop improvement. Front. Plant Sci. 7:997.

Lehmann, S., Serrano, M., L'Haridon, F., Tjamos, S. E., and Metraux, J.-P. 2015. Reactive oxygen species and plant resistance to fungal pathogens. Phytochemistry 112:54-62.

Li, Y., Beisson, F., Koo, A. J. K., Molina, I., Pollard, M., and Ohlrogge, J. 2007. Identification of acyltransferases required for cutin biosynthesis and production of cutin with suberin-like monomers. Proc. Natl. Acad. Sci. U.S.A. 104:18339-18344.

Li-Beisson, Y., Shorrosh, B., Beisson, F., Andersson, M. X., Arondel, V., Bates, P. D., Baud, S., Bird, D., Debono, A., Durrett, T. P., Franke, R. B., Graham, I. A., Katayama, K., Kelly, A. A., Larson, T., Markham, J. E., Miquel, M., Molina, I., Nishida, I., Rowland, O., Samuels, L., Schmid, K. M., Wada, H., Welti, R., Xu, C., Zallot, R., and Ohlrogge, J. 2013. Acyl-lipid metabolism. Arabidopsis Book 11:e0161.

Meier, S., Bastian, R., Donaldson, L., Murray, S., Bajic, V., and Gehring, C. 2008. Co-expression and promoter content analyses assign a role in biotic and abiotic stress responses to plant natriuretic peptides. BMC Plant Biol. 8:24.

Nawrath, C., Schreiber, L., Franke, R.B., Geldner, N., Reina-Pinto, J.J., and Kunst, L. 2013. Apoplastic diffusion barriers in Arabidopsis. The Arabidopsis Book 11:e0167.

Nühse, T. S., Peck, S. C., Hirt, H., and Boller, T. 2000. Microbial elicitors induce activation and dual phosphorylation of the Arabidopsis thaliana MAPK 6. J. Biol. Chem. 275:7521-7526.

Pieterse, C. M. J., Leon-Reyes, A., Van der Ent, S., and Van Wees, S. C. M. 2009. Networking by small-molecule hormones in plant immunity. Nat. Chem. Biol. 5:308-316.

Ramonell, K. M., Zhang, B., Ewing, R. M., Chen, Y., Xu, D., Stacey, G., and Somerville, S. 2002. Microarray analysis of chitin elicitation in Arabidopsis thaliana. Mol. Plant Pathol. 3:301-311.

Reina-Pinto, J. J., and Yephremov, A. 2009. Surface lipids and plant defenses. Plant Physiol. Biochem. 47:540-549.

Reuber, T. L., and Ausubel, F. M. 1996. Isolation of Arabidopsis genes that differentiate between resistance responses mediated by the RPS2 and RPM1 disease resistance genes. Plant Cell 8:241-249.

Robatzek, S., Chinchilla, D., and Boller, T. 2006. Ligand-induced endocytosis of the pattern recognition receptor FLS2 in Arabidopsis. Genes Dev. 20:537-542.

Roetschi, A., Si-Ammour, A., Belbahri, L., Mauch, F., and Mauch-Mani, B. 2001. Characterization of an Arabidopsis-Phytophthora pathosystem: Resistance requires a functional PAD2 gene and is independent of salicylic acid, ethylene and jasmonic acid signalling. Plant J. 28:293-305.

Sadler, C., Schroll, B., Zeisler, V., Waßmann, F., Franke, R., and Schreiber, L. 2016. Wax and cutin mutants of Arabidopsis: Quantitative characterization of the cuticular transport barrier in relation to chemical composition. Biochim. Biophys. Acta 1861:1336-1344.

Salinas-Mondragón, R. E., Garcidueñas-Piña, C., and Guzmán, P. 1999. Early elicitor induction in members of a novel multigene family coding for highly related RING-H2 proteins in Arabidopsis thaliana. Plant Mol. Biol. 40:579-590.
Schlaeppi, K., Abou-Mansour, E., Buchala, A., and Mauch, F. 2010. Disease resistance of Arabidopsis to Phytophthora brassicae is established by the sequential action of indole glucosinolates and camalexin. Plant J. 62: 840-851.

Schlaeppi, K., Bodenhausen, N., Buchala, A., Mauch, F., and Reymond, P. 2008. The glutathione-deficient mutant pad2-1 accumulates lower amounts of glucosinolates and is more susceptible to the insect herbivore Spodoptera littoralis. Plant J. 55:774-786.

Schmittgen, T. D., and Livak, K. J. 2008. Analyzing real-time PCR data by the comparative $\mathrm{C}_{\mathrm{T}}$ method. Nat. Protoc. 3:1101-1108.

Schreiber, L. 2010. Transport barriers made of cutin, suberin and associated waxes. Trends Plant Sci. 15:546-553.

Schweizer, F., Fernández-Calvo, P., Zander, M., Diez-Diaz, M., Fonseca, S., Glauser, G., Lewsey, M. G., Ecker, J. R., Solano, R., and Reymond, P. 2013. Arabidopsis basic helix-loop-helix transcription factors MYC2, MYC3, and MYC4 regulate glucosinolate biosynthesis, insect performance, and feeding behavior. The Plant Cell Online.

Serrano, M., Coluccia, F., Torres, M., L'Haridon, F., and Métraux, J.-P. 2014. The cuticle and plant defense to pathogens. Front. Plant Sci. 5:274.

Serrano, M., and Guzmán, P. 2004. Isolation and gene expression analysis of Arabidopsis thaliana mutants with constitutive expression of ATL2, an early elicitor-response RING-H2 zinc-finger gene. Genetics 167:919-929.

Serrano, M., Parra, S., Alcaraz, L. D., and Guzmán, P. 2006. The ATL gene family from Arabidopsis thaliana and Oryza sativa comprises a large number of putative ubiquitin ligases of the RING-H2 type. J. Mol. Evol. 62:434-445.

Spanu, P., Grosskopf, D. G., Felix, G., and Boller, T. 1994. The apparent turnover of 1-aminocyclopropane-1-carboxylate synthase in tomato cells is regulated by protein phosphorylation and dephosphorylation. Plant Physiol. 106:529-535.

Survila, M., Davidsson, P. R., Pennanen, V., Kariola, T., Broberg, M., Sipari, N., Heino, P., and Palva, E. T. 2016. Peroxidase-generated apoplastic ROS impair cuticle integrity and contribute to DAMP-elicited defenses. Front. Plant Sci. 7:1945.

Tang, D., Simonich, M. T., and Innes, R. W. 2007. Mutations in LACS2, a long-chain acyl-coenzyme A synthetase, enhance susceptibility to avirulent Pseudomonas syringae but confer resistance to Botrytis cinerea in Arabidopsis. Plant Physiol. 144:1093-1103.

Thomma, B. P. H. J., Penninckx, I. A. M. A., Broekaert, W. F., and Cammue, B. P. A. 2001. The complexity of disease signaling in Arabidopsis. Curr. Opin. Immunol. 13:63-68.

Thordal-Christensen, H., Zhang, Z., Wei, Y., and Collinge, D. B. 1997. Subcellular localization of $\mathrm{H}_{2} \mathrm{O}_{2}$ in plants. $\mathrm{H}_{2} \mathrm{O}_{2}$ accumulation in papillae and hypersensitive response during the barley powdery mildew interaction. Plant J. 11:1187-1194.

Tsuda, K., and Somssich, I. E. 2015. Transcriptional networks in plant immunity. New Phytol. 206:932-947.

Tullai, J. W., Schaffer, M. E., Mullenbrock, S., Sholder, G., Kasif, S., and Cooper, G. M. 2007. Immediate-early and delayed primary response genes are distinct in function and genomic architecture. J. Biol. Chem. 282:23981-23995.

Verhage, A., van Wees, S. C. M., and Pieterse, C. M. J. 2010. Plant immunity: It's the hormones talking, but what do they say? Plant Physiol. 154:536-540.

Voisin, D., Nawrath, C., Kurdyukov, S., Franke, R. B., Reina-Pinto, J. J., Efremova, N., Will, I., Schreiber, L., and Yephremov, A. 2009. Dissection of the complex phenotype in cuticular mutants of Arabidopsis reveals a role of SERRATE as a mediator. PLoS Genet. 5:e1000703.

von Saint Paul, V., Zhang, W., Kanawati, B., Geist, B., Faus-Kessler, T., Schmitt-Kopplin, P., and Schäffner, A. R. 2011. The Arabidopsis glucosyltransferase UGT76B1 conjugates isoleucic acid and modulates plant defense and senescence. Plant Cell 23:4124-4145.

Wendehenne, D., Lamotte, O., Frachisse, J.-M., Barbier-Brygoo, H., and Pugin, A. 2002. Nitrate efflux is an essential component of the cryptogein signaling pathway leading to defense responses and hypersensitive cell death in tobacco. Plant Cell 14:1937-1951.

Xia, Y., Gao, Q.-M., Yu, K., Lapchyk, L., Navarre, D., Hildebrand, D., Kachroo, A., and Kachroo, P. 2009. An intact cuticle in distal tissues is essential for the induction of systemic acquired resistance in plants. Cell Host Microbe 5:151-165.

Xing, S., van Deenen, N., Magliano, P., Frahm, L., Forestier, E., Nawrath, C., Schaller, H., Gronover, C. S., Prüfer, D., and Poirier, Y. 2014. ATP citrate lyase activity is post-translationally regulated by sink strength and impacts the wax, cutin and rubber biosynthetic pathways. Plant J. 79:270-284.

Zeier, J., Pink, B., Mueller, M. J., and Berger, S. 2004. Light conditions influence specific defence responses in incompatible plant-pathogen interactions: Uncoupling systemic resistance from salicylic acid and PR-1 accumulation. Planta 219:673-683. 
Zhang, H., Huang, L., Dai, Y., Liu, S., Hong, Y., Tian, L., Huang, L., Cao, Z., Li, D., and Song, F. 2015. Arabidopsis AtERF15 positively regulates immunity against Pseudomonas syringae pv. tomato DC3000 and Botrytis cinerea. Front. Plant Sci. 6:686.

Zhao, Y., Hull, A. K., Gupta, N. R., Goss, K. A., Alonso, J., Ecker, J. R., Normanly, J., Chory, J., and Celenza, J. L. 2002. Trp-dependent auxin biosynthesis in Arabidopsis: Involvement of cytochrome P450s CYP79B2 and CYP79B3. Genes Dev. 16:3100-3112.

Zipfel, C. 2014. Plant pattern-recognition receptors. Trends Immunol. 35: 345-351.

Zipfel, C., Kunze, G., Chinchilla, D., Caniard, A., Jones, J. D. G., Boller, T., and Felix, G. 2006. Perception of the bacterial PAMP EF-Tu by the receptor EFR restricts Agrobacterium-mediated transformation. Cell 125:749-760

Zipfel, C., Robatzek, S., Navarro, L., Oakeley, E. J., Jones, J. D. G., Felix, G., and Boller, T. 2004. Bacterial disease resistance in Arabidopsis through flagellin perception. Nature 428:764-767.

\section{AUTHOR-RECOMMENDED INTERNET RESOURCES}

agriGO toolkit: http://bioinfo.cau.edu.cn/agriGO

Primer3 software: http://bioinfo.ut.ee/primer3

FiRe 2.2 program: http://www.unifr.ch/plantbio/FiRe/main.html 